\title{
An effective spray drift-reducing method for a plant-protection unmanned aerial vehicle
}

\author{
Yayong Chen, Chaojun Hou, Yu Tang*, Jiajun Zhuang, Jintian Lin, Shaoming Luo \\ (Academy of Contemporary Agricultural Engineering Innovations, Zhongkai University of Agriculture and Engineering, \\ Guangzhou 510225, China)
}

\begin{abstract}
A spraying system for a plant-protection unmanned aerial vehicle (UAV) was designed to reduce spray drift. A custom low-speed wind tunnel was constructed to generate a wind speed ranging from 0 to $5.92 \mathrm{~m} / \mathrm{s}$. The results showed that the wind speed was attenuated with an increase in distance. To compensate for the attenuation, a linear-fitting model was adopted. Then, the relationship between the spraying pressure and atomization rate was analyzed, and a fuzzy algorithm was adopted to adjust the spraying angle and pressure according to the wind speed and its changing rate. Finally, an evaluation of the proposed system in the compensated wind tunnel was conducted, and the drift distance was reduced by $33.7 \%$ compared with the system without adjustment of the spraying angle and pressure.
\end{abstract}

Keywords: plant-protection UAV, spray drift, spraying pressure, spraying angle, fuzzy algorithm

DOI: $10.25165 /$ j.jjabe.20191205.4289

Citation: Chen Y Y, Hou C J, Tang Y, Zhuang J J, Lin J T, Luo S M. An effective spray drift-reducing method for a plant-protection unmanned aerial vehicle. Int J Agric \& Biol Eng, 2019; 12(5): 14-20.

\section{Introduction}

Plant-protection unmanned aerial vehicles (UAVs) are used to spray pesticides and have become increasingly common, due to the speed and effectiveness of the spraying operation ${ }^{[1-3]}$. During the spraying process, when the pesticide liquid is atomized through the nozzle, droplets of less than $150 \mu \mathrm{m}$ are more sensitive to drift caused by wind ${ }^{[4,5]}$, which can lead to damage to susceptible off-target crops, reduce the effectiveness of the pesticide, and cause environmental contamination, such as water pollution and illegal pesticide residues ${ }^{[6,7]}$. Therefore, the spray drift of pesticides away from the target compromises the effectiveness of UAV spraying and limits its wide application ${ }^{[8,9]}$.

Recently, many researchers have focused on the reduction of spray drift and have found that the nozzle type, droplet size, working path of the UAV, and wind speed are the main influencing factors ${ }^{[10-12]}$. Torrent et al. ${ }^{[13]}$ reported that the nozzle type is the one of the most important factors influencing spray drift. Foque et al. ${ }^{[14]}$ studied spraying performance on conical bay laurel using different spray nozzles and found that an extended range flat fan was the optimal nozzle type, due to the increased uniformity of its spray distribution. To reduce spray drift and pesticide residues, Zhao et al. ${ }^{[15]}$ investigated residues sprayed on wheat using different spraying nozzles and found that the combination of a

Received date: 2018-08-01 Accepted date: 2019-01-04

Biographies: Yayong Chen, Graduate student, research interests: agriculture information technology, Email: 511520211@qq.com; Chaojun Hou, PhD, Associate Professor, research interests: agriculture engineering, Email: hcj_carson@126.com; Jiajun Zhuang, PhD, Lecturer, research interests: agriculture information technology, Email: jiajunzhuang@126.com; Jintian Lin, PhD, Professor, research interests: insect ecology, Email: linjtian@163.com; Shaoming Luo, $\mathrm{PhD}$, Professor, research interests: intelligent agriculture equipment, Email: smluo@gdut.edu.cn. The first two authors should be considered as co-first authors.

*Corresponding author: Yu Tang, PhD, Professor, research interests: agricultural aviation application. College of Automation, Zhongkai University of Agriculture and Engineering, Guangzhou 510225, China. Tel: +86-2089003790, Email: ty2008@zhku.edu.cn, tangyu_mycauc@163.com. flat-fan nozzle (AD120-02) and a guided-baffle shield sprayer achieved the optimum spray drift for these plants. Mercer ${ }^{[16]}$ developed a spray capture model for the flow-through and over a shelterbelt to determine the capture efficiency of shelterbelts. Cock et al. ${ }^{[17]}$ determined the optimum range of droplet sizes for applying an herbicide with a boom-sprayer using a combined Lagrangian droplet transport and retention model and found that the drift was decreased $67 \%$ when the medium droplet size was $225 \mu \mathrm{m}$. Hilz et al. ${ }^{[18]}$ studied the relevant physical properties of agricultural spray liquids and found that drift risk was often correlated with spray droplet size, particularly with the percentage of fine spray droplets. Miranda-Fuentes et al. ${ }^{[19]}$ studied the parameters affecting the droplet size in pneumatic spraying to reduce spray drift and found that variations in the diameter of the spout significantly changed the droplet size. Faial et al. ${ }^{[20]}$ proposed a computer-based system with route metaheuristics that could adapt the route of UAV spraying to different wind conditions. Wang et al. ${ }^{[21]}$ studied the spray drift of a UAV with a pre-defined flight path at wind speeds ranging from 0.76 to $5.5 \mathrm{~m} / \mathrm{s}$ and reported that $90 \%$ of the drift was deposited within a range of 9.3-14.5 m, and the safe area for spraying was more than $15 \mathrm{~m}$. Heidary et al. ${ }^{[22]}$ studied the effect of wind speed and nozzle type on spray drift in a wind tunnel and found that an increase in wind speed led to an increase in lateral spray drift values for all modalities. Alves et al. ${ }^{[23]}$ studied the drift from dicamba application under several wind speeds in a wind tunnel and found that when flat-fan nozzles were used, the spray drift increased exponentially as wind speed increased, whereas when a nozzle was used, the spray drift increased linearly with the increase in wind speed. Ellis et al. ${ }^{[24]}$ investigated a mathematical model of the droplet drift mass center distance versus electrostatic voltage and wind speed to determine optimum operational parameters for a conical electrostatic nozzle. Although many researchers have systematically investigated the reduction of spray drift, the use of a fuzzy algorithm method to adjust the spraying angle and pressure to achieve reduction of spray drift has seldom been reported.

In this study, a spraying system using a fuzzy algorithm to 
achieve reduction of spray drift was designed. The speed of the wind attenuation model was established to compensate for the spray drift. Thus, the fuzzy decision table was determined by investigating the spraying angle and spraying pressure, where the relationship between the spraying pressure and spraying atomization rate (SAR) was studied to generate a control parameter of spraying pressure. An evaluation of the proposed system was conducted in a compensated wind tunnel.

\section{Materials and methods}

\subsection{Spraying system hardware}

The four-axis UAV (ZHKU-0404-01) manufactured by Zhongkai University of Agriculture and Engineering was used in the experiments, as shown in Figure 1. Its key parameters are listed in Table 1. The spraying system mounted on the UAV is mainly composed of wind sensors, a controller and spraying parts. Specifically, a wind speed detector (QS-FS01) and a wind direction detector (QS-FX01) in a wind sensor module are used to measure wind speed, which are located at a special position far from the wind fields generated by the UAV rotors. Arduino (MEGA2560-R3) is adopted as the controller module. The spraying parts include spraying nozzles (VP110-015), a water pump (QP-2203) and a steering motor (MG995). The water pump is used to adjust the spraying pressure, and the steering motor is used to control the spraying angle of the nozzle via a torque adjustment structure. The spraying angle can be adjusted between $0^{\circ}$ (in the vertical direction) and $90^{\circ}$ (in the horizontal direction).

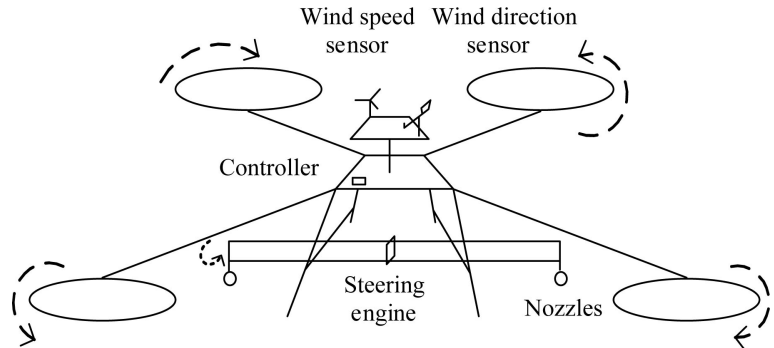

a. Diagram of the hardware configuration on the UAV

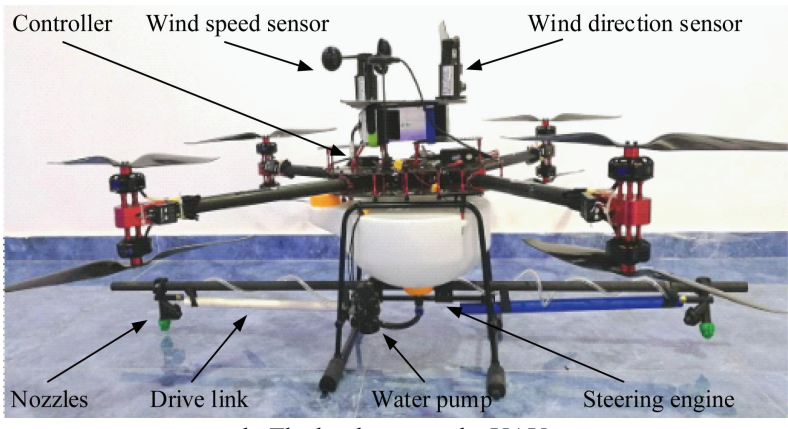

b. The hardware on the UAV

Figure 1 Spraying system hardware

Table 1 Key parameters of the ZHKU-0404-01 UAV

\begin{tabular}{lc}
\multicolumn{1}{c}{ Item } & Parameter \\
\hline Axis & 4 \\
Flight speed $/ \mathrm{m} \cdot \mathrm{s}^{-1}$ & $1-5$ \\
Tank capacity $/ \mathrm{L}$ & 15 \\
Nozzle number & $2-4$ \\
Nozzle type & Flat fan \\
Spray boom length $/ \mathrm{m}$ & 2.2 \\
Spraying pressure $/ \mathrm{MPa}$ & $0.2-1.0$ \\
Payload $/ \mathrm{kg}$ & 27 \\
Flight time $/$ min & 10 \\
\hline
\end{tabular}

According to the analog-to-digital converter method ${ }^{[25]}$, the effective wind speed, $\mathrm{W}$, can be calculated as follows:

$$
W=W_{0} \times \sin (\theta)
$$

where, $W_{0}$ is the detected wind speed, $\mathrm{m} / \mathrm{s}$; and $\theta$ is the angle between the direction of wind and the flying direction of the UAV.

\subsection{Spraying system software}

The flowchart of the software system is shown in Figure 2. After the initialization of the system, the wind speed and wind direction are detected by the wind sensors using a $0.1 \mathrm{~s}$ sampling period. When the wind speed is less than $5.92 \mathrm{~m} / \mathrm{s}$ and the changing rate of the wind speed is less than $1.5 \mathrm{~m} / \mathrm{s}^{2}$, the work condition is satisfied, and the system will query the fuzzy decision table, which is determined as described in Section 3.3. Then, the spraying pressure and spraying angle are calculated via the proposed fuzzy algorithm and translated to the water pump and steering motor, respectively. The spraying pressure and spraying angle are saved in the electrically erasable programmable read only memory (EEPROM) in the control core and sent to an upper computer via wireless transmission for data analysis using LabVIEW. Lastly, the system continues to receive wind speed and wind direction data and then follows the aforementioned loop.

Denoting wind speed as $W(t)$ at time $t$, the changing rate of wind speed $g(t)$ at time $t$ is defined as follows:

$$
g(t)=\frac{W(t+\Delta t)-W(t)}{\Delta t}
$$

where, $\Delta t=0.1 \mathrm{~s}$.

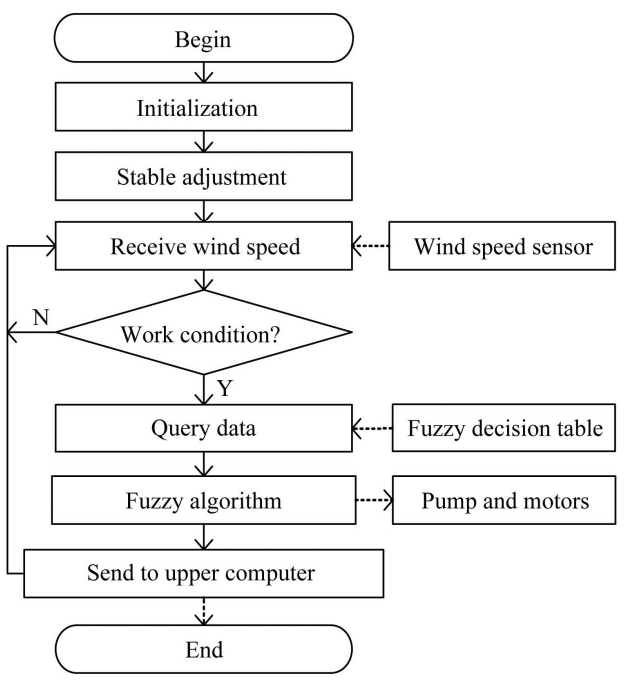

Figure 2 Program flow for adjusting the spraying angle and spraying pressure

The detailed scheme of the fuzzy algorithm is shown in Figure 3. The effective wind speed $(W)$ was calculated using Equation (1). In the process of fuzzification, the membership of the wind speed and the changing rate of wind speed are determined according to the membership functions shown in Figure 4 described below. Then, the decision table is used to identify the spraying pressure and angle with the minimum drift distance during fuzzy decision making, while the optimal spraying pressure and angle are determined during defuzzification.

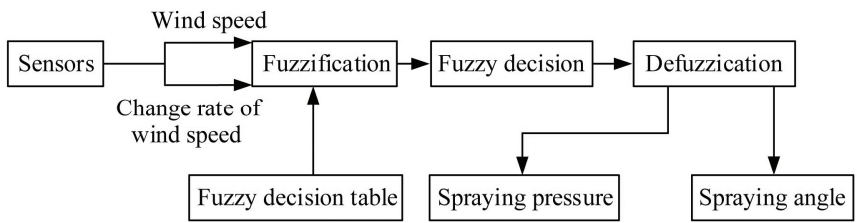

Figure 3 Flowchart of the fuzzy algorithm 

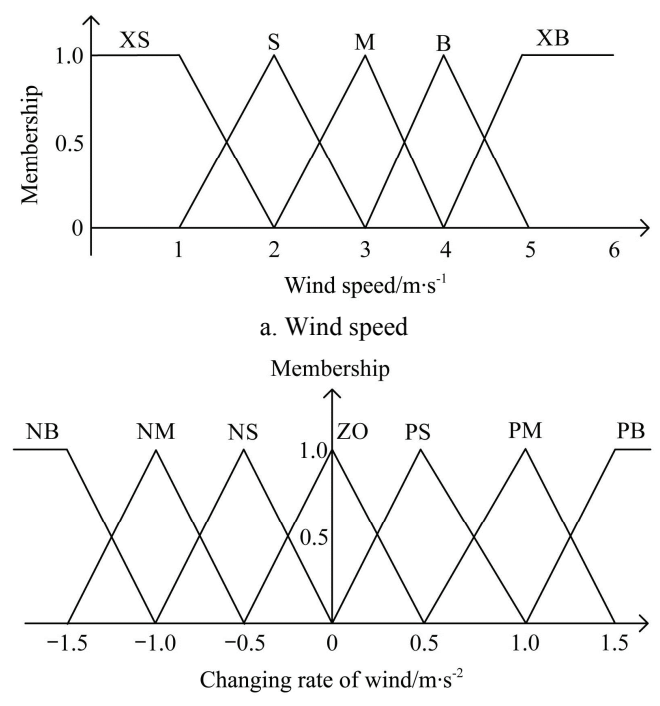

b. Changing rate of wind speed

Figure 4 Membership functions of the input variables

The membership function during the process of fuzzification is considered as follows. The wind speed under working conditions ranges from 0 to $5.92 \mathrm{~m} / \mathrm{s}$ and is divided into five intersection groups: XS (extra small), S (small), M (medium), B (big), and XB (extra big). The changing rate of the wind speed ranges from $-1.5 \mathrm{~m} / \mathrm{s}^{2}$ to $1.5 \mathrm{~m} / \mathrm{s}^{2}$ and is divided into seven intersection groups, designated NB (negative big), NM (negative middle), NS (negative small), ZO (zero), PS (positive small), PM (positive middle), and $\mathrm{PB}$ (positive big), respectively.

As for the defuzzification, the output spraying angle or spraying pressure is represented by $u$ as follows:

$$
u(x)=\frac{\sum_{i=1}^{n} \mu_{i}(x) \times U_{i}}{\sum_{i=1}^{n} \mu_{i}(x)}
$$

where, $x$ is the input such as wind speed or changing rate of wind speed; $\mu_{i}(x)$ is the membership function of $i$-th group; $U_{i}$ is the center value of spraying angle or spraying pressure for $i$-th group, and $n$ is the number of groups.

\subsection{Wind tunnel design}

Because the spraying operation was conducted at a height of approximately $1.20 \mathrm{~m}$ above the crops, a low-speed wind tunnel was designed to support a suitably windy environment for the experiments. As shown in Figure 5, a wind tunnel with a size of $1.20 \mathrm{~m} \times 1.20 \mathrm{~m} \times 3.50 \mathrm{~m}$ was constructed, mainly comprised of a power section, stability section, compression section, diffusion section, and an auxiliary circuit and control component. The power section consisted of four brushless DC motors with a maximum working current of $50 \mathrm{~A}$. The stability section was mainly composed of a damping net and honeycomb, which could reduce the flow and swirl state of the air flow and improve the uniformity of the airflow ${ }^{[26]}$. The compression section was smaller by $0.5 \mathrm{~m}$, to compress and accelerate the air flow; thus, the air stream was polymerized, and the kinetic energy of the air flow increased. The main purpose of the diffusion section was to restore the pressure energy of the air flow. The four brushless DC motors were controlled by an STM32 (STMicroelectronics STM32F107).

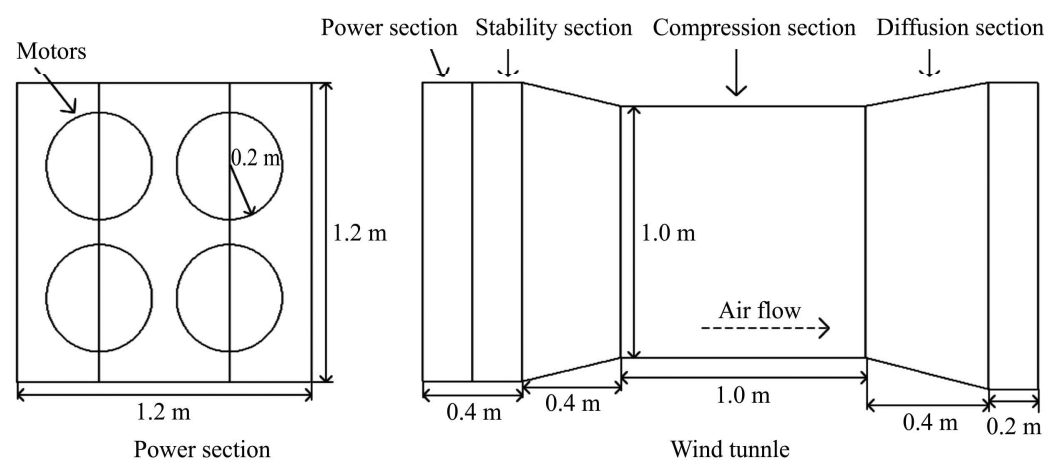

a. Wind tunnel schematic

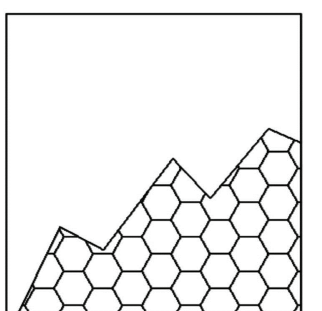

Damping net in stability section

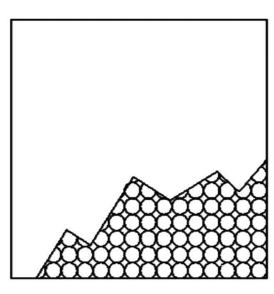

Honeycomb in stability section

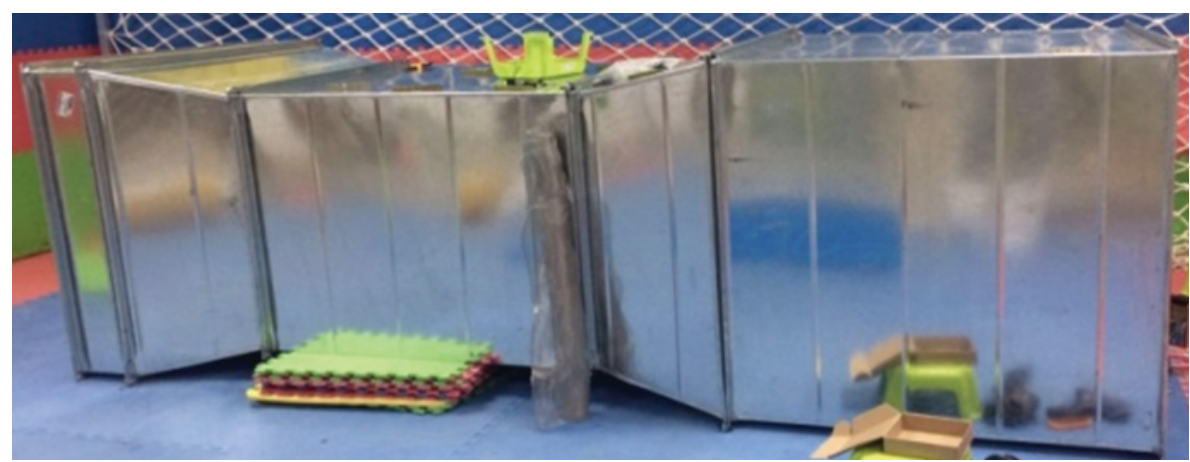

b. Wind tunnel

Figure 5 Diagram of the wind tunnel

\subsection{Experimental procedure}

To validate the performance of the proposed spraying system with a fuzzy algorithm, three experiments were carried out. The first experiment was designed to compensate for the spray drift caused by an increasing distance to the wind tunnel, where the relationship between wind speed and the drift distance was studied using a wind attenuation model. Then, the relationship between the spraying pressure and atomization was explored using a non-linear regression model to determine the control parameters of spraying pressure which were used in the third experiment. The working wind speed at different settings of spraying pressure and angle was measured to calculate the fuzzy decision table. Finally, 
the performance of the whole proposed system was evaluated using the wind tunnel, as shown in Figure 6.

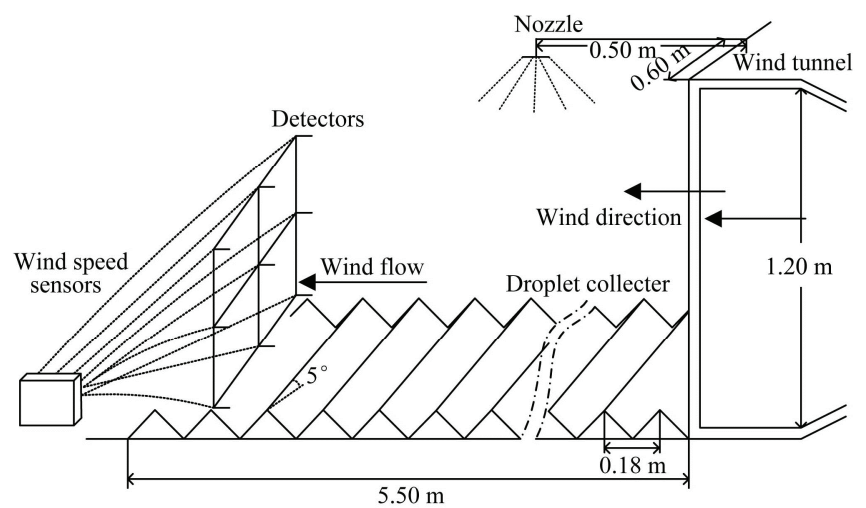

Figure 6 Environment of spraying experiment

The atmospheric pressure of the experimental environment was $109.5 \mathrm{kPa}$ in a closed lab with a temperature of $28.3^{\circ} \mathrm{C}$. The wind tunnel was set in the center of the lab approximately $12 \mathrm{~m}$ from the surrounding isolation walls, where $10 \mathrm{~m}$ distance was reserved. The nozzle was fixed at a height of $1.2 \mathrm{~m}$ and situated $0.5 \mathrm{~m}$ from the wind tunnel. A droplet collector with a size of $5.5 \mathrm{~m} \times 1.6 \mathrm{~m}$ was placed in front of the wind tunnel, which was tilted $5^{\circ}$ with respect to the ground plane. The groove of the droplet collector was $0.18 \mathrm{~m}$ and at an angle to the wind direction. To test the wind speed, the wind speed detector was placed at the side of the air flow and the nine sensors of the detector formed a $3 \times 3$ matrix in an area of $0.9 \mathrm{~m} \times 0.9 \mathrm{~m}$.

\section{Results and discussion}

\subsection{Evaluation on wind attenuation from wind tunnel}

The wind speed at different distances to the outlet was measured by the sensors under several settings of initial wind speed. The sensors were situated at a distance ranging from 0 to $4.5 \mathrm{~m}$ from the wind tunnel at an interval of $0.5 \mathrm{~m}$. The wind speed at each spot was measured by the nine sensors and the average value was adopted. This experiment was repeated 10 times and the average value was used to generate the wind speed shown in Figure 7. The results showed that, when the distance to the outlet of wind tunnel was $4.5 \mathrm{~m}$, the wind speed decreased approximately $1.74 \mathrm{~m} / \mathrm{s}$ with an initial wind speed of $5.92 \mathrm{~m} / \mathrm{s}$ and decreased approximately $1.12 \mathrm{~m} / \mathrm{s}$ with an initial wind speed of $1.29 \mathrm{~m} / \mathrm{s}$. When the initial wind speed is $5.92 \mathrm{~m} / \mathrm{s}$, the speed decreased approximately $0.34 \mathrm{~m} / \mathrm{s}$ as the distance to the outlet of the wind tunnel was within a range of $2.5 \mathrm{~m}$ to $4.5 \mathrm{~m}$. However, the speed decreased approximately $1.84 \mathrm{~m} / \mathrm{s}$ when the distance was within a range of 0 to $2.5 \mathrm{~m}$

The relationship between wind speed and distance to the outlet of the wind tunnel under different initial wind speeds was modeled. The wind speed $W$ can be determined in a multiple regression model as follows:

$$
W=0.48+0.82 W_{0}-0.40 d
$$

where, $d$ is the distance to the outlet of the wind tunnel, $\mathrm{m} ; W_{0}$ is the initial wind speed, $\mathrm{m} / \mathrm{s}$; and RMSE $=0.29 \mathrm{~m} / \mathrm{s}$ and $R^{2}=0.89$. Figure 8 shows the regression surface of the wind speed to distance and initial wind speed.

It was assumed that the droplets moved at the same speed and direction as the wind flow. The theoretical drift distance $D(t)$ at the constant initial wind speed of $W_{0}$ varied with $t$ and can be calculated as follows:

$$
D(t)=W_{0} t
$$

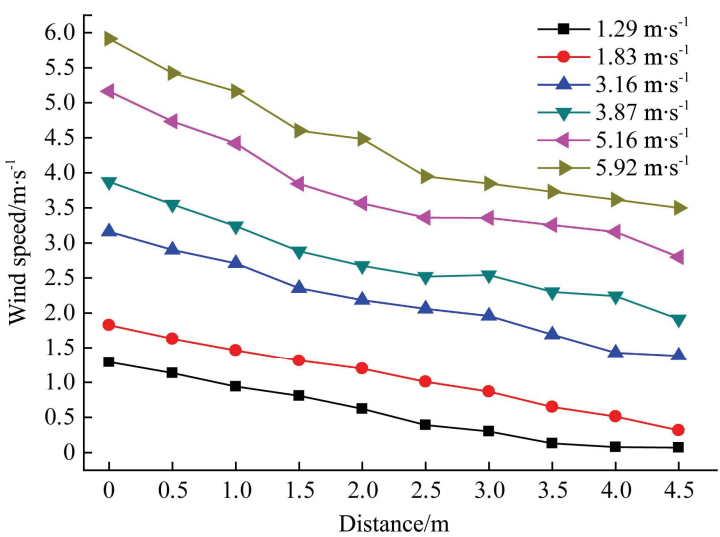

Figure 7 Wind speed at different distances to the wind tunnel under several initial wind speeds

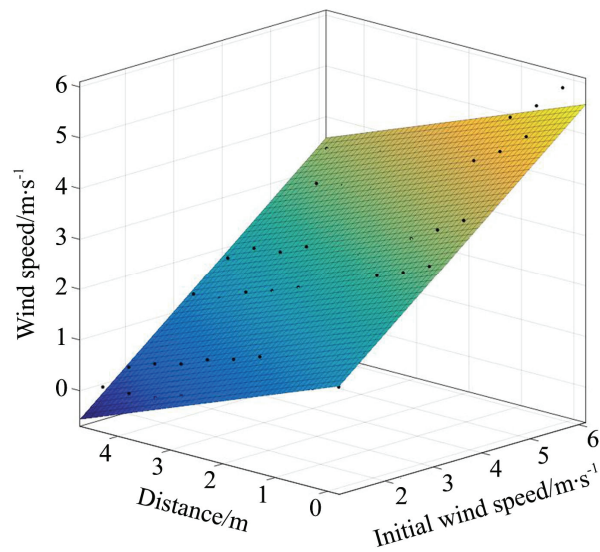

Figure 8 Regression surface of wind speed to distance and initial wind speed

As shown in Figure 7, the wind speed decreased as the distance to the outlet of the wind tunnel increased, thus the actual drift distance was much less than the theoretical drift distance. To calibrate the actual drift distance under a constant wind speed, the compensation distance $d_{c}$ was determined as follows:

$$
d_{c}=D(T)-\int_{0}^{T} W(t) \mathrm{d} t
$$

where, $T$ is the time of droplet moving, $\mathrm{s}$; and $W(t)$ is derived from Equation (6). To evaluate the effectiveness of the compensation distance $d_{c}$, the spraying experiment was conducted under a spraying angle of $0^{\circ}$ and a spraying pressure of $200 \mathrm{kPa}$. Figure 9 shows the theoretical drift distance, actual drift distance and the corrected drift distance, where the actual drift distance was measured during the spraying experiment, the theoretical drift distance was calculated using Equation (5), and the corrected drift distance was calibrated by the addition of the actual drift distance and the compensation distance $d_{c}$.

Figure 9 shows that the theoretical drift distance increased linearly as the wind speed increased. The actual value of spray drift was less than the theoretical value and the error was $0.69 \mathrm{~m}$. Using the compensation distance $d_{c}$, the error between the correction value and theoretical value decreased to $0.41 \mathrm{~m}$. In particular, it was more obvious that the error between the correction value and theoretical value was $0.5 \mathrm{~m}$ on average at wind speeds less than $3 \mathrm{~m} / \mathrm{s}$. However, the error increased considerably as the wind speed increased to greater than $3 \mathrm{~m} / \mathrm{s}$, which may be due to the fact that the assumption of Equation (5) does not hold when the wind speed exceeds $3 \mathrm{~m} / \mathrm{s}$, i.e., the droplets move at a different speed compared to the wind flow. 


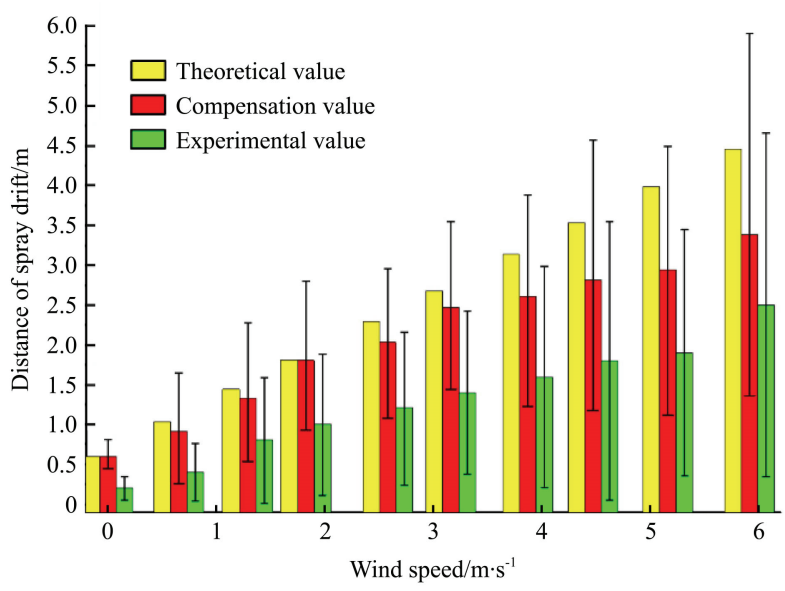

Figure 9 Corrected results of drift distance

3.2 Evaluation of the spraying atomization rate with respect to spraying pressure

Droplet size is an important factor influencing spray drift, which can be controlled by spraying pressure ${ }^{[27-29]}$. In particular, droplets smaller than $150 \mu \mathrm{m}$ are more susceptible to drift ${ }^{[30]}$. Let the spraying atomization rate (SAR) be the percentage accumulation of droplets with a size smaller than $150 \mu \mathrm{m}$, expressed as follows:

$$
S A R=\sum_{d_{i} \leq 150 \mu \mathrm{m}} V_{i} / \sum V_{i}
$$

where, $d_{i}$ is the droplet size, $\mu \mathrm{m}$; and $V_{i}$ is the total volume of droplets with a size from $\left(d_{i-1}, d_{i}\right]$. The volume of droplets was measured using a laser particle size analyzer.

To calculate a series of proper spraying pressure values for the fuzzy algorithm of the spraying system, the relationship between SAR and spraying pressure $p$ was modeled in a logarithmic-fitting fashion as follows:

$$
S A R=-29.55+14.88 \ln (p-29.08), 100 \leq p \leq 500 \mathrm{kPa}
$$

where, $R^{2}=0.94$, and RMSE $=1.39 \%$. Figure 10 shows the relationship of SAR and spraying pressure.

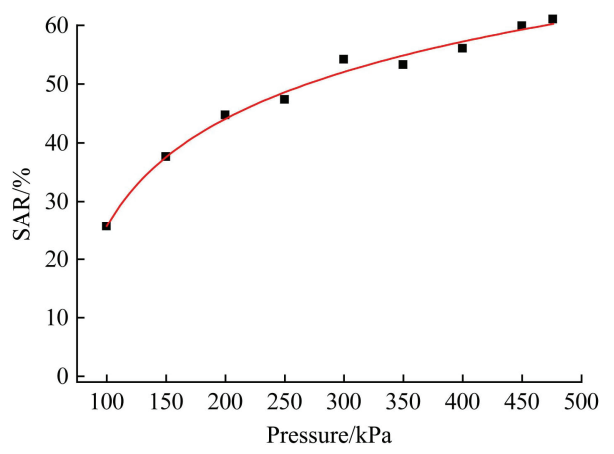

Figure 10 Relationship of SAR and spraying pressure

As shown in Figure 10, when the spraying pressure changed from $100 \mathrm{kPa}$ to $500 \mathrm{kPa}$ the SAR increased from $24 \%$ to $62 \%$. In particular, the SAR changed rapidly from $24 \%$ to $45 \%$ as the pressure increased from $100 \mathrm{kPa}$ to $200 \mathrm{kPa}$, likely due to the atomization performance of the nozzle. The SAR changed slowly from $45 \%$ to $62 \%$ as the pressure increased from $200 \mathrm{kPa}$ to $500 \mathrm{kPa}$, probably due to the different initial speeds of the droplets sprayed from the nozzle under different spraying pressures. The SAR was equally divided into five intervals in a range from $24 \%$ to $62 \%$. As a consequence, the five spraying pressure fuzzy subsets were calculated as $100 \mathrm{kPa}, 143 \mathrm{kPa}, 212 \mathrm{kPa}, 322 \mathrm{kPa}$, and $500 \mathrm{kPa}$, according to the inverse function of Equation (8).

\subsection{Effect of fuzzy algorithm on spray drift reduction}

To determine the fuzzy table of the spraying angle and spraying pressure for the fuzzy algorithm, the relationship between drift distance and spraying angle as well as that between drift distance and spraying pressure was studied, respectively. Table 2 shows the drift distance in different settings of spraying angle from $0^{\circ}$ to $90^{\circ}$, spraying pressure from $100 \mathrm{kPa}$ to $500 \mathrm{kPa}$, and initial wind speed from 0 to $5.92 \mathrm{~m} / \mathrm{s}$.

\begin{tabular}{|c|c|c|c|c|c|c|}
\hline \multirow{2}{*}{ Spraying angle/ $\left({ }^{\circ}\right)$} & \multirow{2}{*}{ Spraying pressure $/ \mathrm{kPa}$} & \multicolumn{5}{|c|}{ Drift distance $/ \mathrm{m}$} \\
\hline & & $0.00 \mathrm{~m} / \mathrm{s}$ & $1.50 \mathrm{~m} / \mathrm{s}$ & $3.00 \mathrm{~m} / \mathrm{s}$ & $4.50 \mathrm{~m} / \mathrm{s}$ & $6.00 \mathrm{~m} / \mathrm{s}$ \\
\hline \multirow{5}{*}{0} & 100 & $0.02 \pm 0.23$ & $0.89 \pm 0.22$ & $2.51 \pm 0.49$ & $2.82 \pm 0.79$ & $3.71 \pm 0.94$ \\
\hline & 143 & $0.10 \pm 0.24$ & $1.00 \pm 0.30$ & $2.59 \pm 0.67$ & $2.92 \pm 0.75$ & $3.99 \pm 1.10$ \\
\hline & 212 & $0.16 \pm 0.27$ & $1.12 \pm 0.48$ & $2.68 \pm 0.80$ & $3.00 \pm 0.81$ & $4.20 \pm 1.45$ \\
\hline & 322 & $0.12 \pm 0.29$ & $1.19 \pm 0.52$ & $2.81 \pm 1.09$ & $3.12 \pm 1.09$ & $4.46 \pm 1.74$ \\
\hline & 500 & $0.13 \pm 0.31$ & $1.31 \pm 0.57$ & $2.90 \pm 1.29$ & $3.42 \pm 1.18$ & $4.53 \pm 2.10$ \\
\hline \multirow{4}{*}{30} & 143 & - & $0.29 \pm 0.28$ & $1.75 \pm 0.91$ & $2.42 \pm 0.90$ & $3.34 \pm 1.35$ \\
\hline & 212 & - & $0.40 \pm 0.31$ & $1.92 \pm 1.12$ & $2.51 \pm 1.12$ & $3.46 \pm 1.54$ \\
\hline & 322 & - & $0.52 \pm 0.45$ & $2.10 \pm 1.30$ & $2.62 \pm 1.27$ & $3.63 \pm 1.73$ \\
\hline & 500 & - & $0.60 \pm 0.67$ & $2.22 \pm 1.53$ & $2.74 \pm 1.32$ & $3.76 \pm 2.02$ \\
\hline \multirow{4}{*}{45} & 100 & - & - & $1.25 \pm 0.70$ & $1.81 \pm 1.05$ & $2.38 \pm 1.32$ \\
\hline & 143 & - & - & $1.38 \pm 0.82$ & $1.95 \pm 1.39$ & $2.57 \pm 1.58$ \\
\hline & 212 & - & - & $1.46 \pm 0.99$ & $2.01 \pm 1.57$ & $2.63 \pm 1.71$ \\
\hline & 500 & - & $0.14 \pm 0.87$ & $1.58 \pm 1.46$ & $2.22 \pm 1.94$ & $3.07 \pm 2.19$ \\
\hline \multirow{5}{*}{60} & 100 & - & - & - & $1.47 \pm 1.59$ & $1.93 \pm 1.44$ \\
\hline & 143 & - & - & - & $1.52 \pm 1.84$ & $2.01 \pm 1.61$ \\
\hline & 212 & - & - & $0.41 \pm 0.75$ & $1.60 \pm 2.00$ & $2.27 \pm 1.79$ \\
\hline & 322 & - & - & $0.52 \pm 0.91$ & $1.72 \pm 2.30$ & $2.33 \pm 1.93$ \\
\hline & 500 & - & - & $0.69 \pm 1.09$ & $1.92 \pm 2.09$ & $2.57 \pm 2.24$ \\
\hline \multirow{5}{*}{90} & 100 & - & - & - & $1.02 \pm 1.35$ & $1.23 \pm 1.03$ \\
\hline & 143 & - & - & - & $1.10 \pm 1.54$ & $1.33 \pm 1.34$ \\
\hline & 212 & - & - & - & $1.26 \pm 1.52$ & $1.48 \pm 1.52$ \\
\hline & 322 & - & - & - & $1.20 \pm 1.79$ & $1.73 \pm 1.84$ \\
\hline & 500 & - & - & $0.10 \pm 0.95$ & $1.49 \pm 2.07$ & $1.93 \pm 2.25$ \\
\hline
\end{tabular}

Table 2 Drift distance in different settings of spraying angle, spraying pressure and initial wind speed

Note: "-" represents data values is close to zero. 
As shown in Table 2, the drift distance increased when the wind speed increased from 0 to $5.92 \mathrm{~m} / \mathrm{s}$. With a fixed value of spraying pressure and initial wind speed, e.g., in the case of $100 \mathrm{kPa}$ and $4.5 \mathrm{~m} / \mathrm{s}$, respectively, the drift distance decreased from $2.82 \mathrm{~m}$ to $1.02 \mathrm{~m}$ when the spraying angle increased from $0^{\circ}$ to $90^{\circ}$. When the spraying angle and initial wind speed were set to $0^{\circ}$ and $4.5 \mathrm{~m} / \mathrm{s}$, respectively, the drift distance was positively correlated to the spraying pressure. Because the changing rate of wind speed would influence the depositional position of the droplets during the spraying process, a proper spraying pressure should be adjusted in terms of wind speed to guarantee a small drift distance. Table 3 lists the control parameters according to different settings of the changing rate of initial wind speed.

Table 3 Fuzzy decision table of spraying angle and pressure

\begin{tabular}{cccccc}
\hline \multirow{2}{*}{$\begin{array}{c}\text { Changing rate of } \\
\text { wind speed }\end{array}$} & \multicolumn{5}{c}{ Wind speed } \\
\cline { 2 - 6 } & $\mathrm{L}$ & $\mathrm{S}$ & $\mathrm{M}$ & $\mathrm{B}$ & $\mathrm{XB}$ \\
\hline NB & $0 / 100^{*}$ & $0 / 143$ & $0 / 500$ & $15 / 322$ & $60 / 143$ \\
NM & $0 / 143$ & $0 / 212$ & $30 / 500$ & $30 / 322$ & $60 / 143$ \\
NS & $0 / 212$ & $0 / 500$ & $30 / 322$ & $45 / 212$ & $60 / 143$ \\
ZO & $0 / 500$ & $30 / 322$ & $45 / 212$ & $60 / 143$ & $90 / 100$ \\
PS & $0 / 322$ & $45 / 212$ & $60 / 143$ & $90 / 100$ & $90 / 100$ \\
PM & $15 / 212$ & $60 / 143$ & $75 / 100$ & $90 / 100$ & - \\
PB & $30 / 143$ & $60 / 100$ & $90 / 100$ & - & - \\
\hline
\end{tabular}

Note: The number $0 / 100$ means that the spraying angle is $0^{\circ}$ and the pressure is $100 \mathrm{kPa}$, respectively.

The proposed system was mounted on the UAV described in Section 2.1 and tested in the wind tunnel. Figure 11 shows the results of spray drift compensation, which shows that the drift distance decreased by $33.7 \%$ compared with the system without incorporating the proposed procedure.

As shown in Figure 11, better compensation results could be found within the initial wind speed range of from 0 to $2.5 \mathrm{~m} / \mathrm{s}$, indicating that the drift distance was less than $0.5 \mathrm{~m}$ with an error less than $0.3 \mathrm{~m}$. However, when the initial wind speed was in the interval between $2.5-5.92 \mathrm{~m} / \mathrm{s}$, the drift distance changed from $0.6 \mathrm{~m}$ to $1.2 \mathrm{~m}$ and the corresponding error increased from $0.3 \mathrm{~m}$ to $1.4 \mathrm{~m}$, which was probably caused by the different droplet sizes.

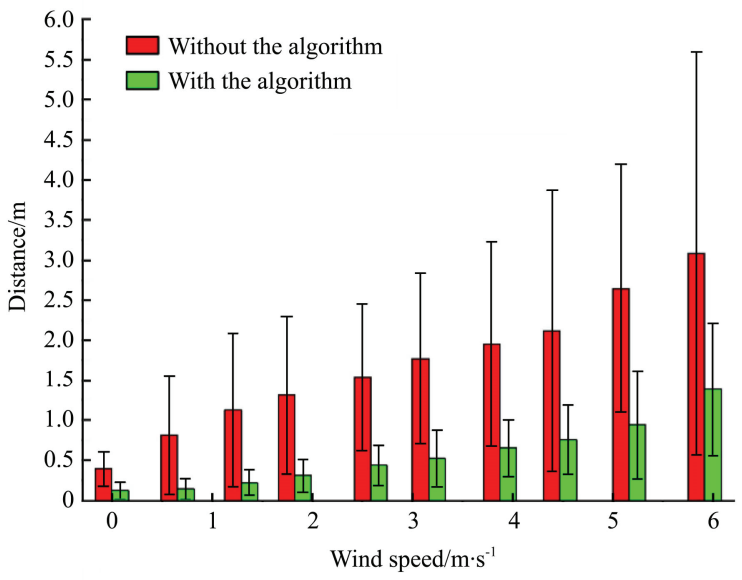

Figure 11 Drift distance of the proposed system with fuzzy algorithm and without fuzzy algorithm

\section{Conclusions}

To reduce spray drift, an effective method of adjusting the spraying angle and spraying pressure for a plant-protection UAV was investigated in this study. The main conclusions are as follows:

(1) The wind speed attenuation of the wind tunnel was first studied and modeled using a multiple linear regression method. The $R^{2}$ was 0.89 , and the RMSE was $0.29 \mathrm{~m} / \mathrm{s}$; these results indicate that the model can fit the experimental data perfectly well. Using the compensation model of wind attenuation, the drift distance can be calibrated to a theoretical value with an error of $0.41 \mathrm{~m}$, compared with that without calibration with an error of $0.69 \mathrm{~m}$.

(2) The relationship between SAR and the spraying pressure was established using a non-linear regression model. The $R^{2}$ was 0.94 , and the RMSE was $1.78 \%$. Then, by equaling the range of SAR according to the regression model, the fuzzy set of spraying pressure was divided into 5 elements, i.e., $100 \mathrm{kPa}, 143 \mathrm{kPa}$, $212 \mathrm{kPa}, 322 \mathrm{kPa}$, and $500 \mathrm{kPa}$.

(3) The working wind speed at different settings of spraying pressure and spraying angle was measured to determine the decision table using a fuzzy algorithm. The experimental result showed that the drift distance decreased by $33.7 \%$ compared with the spraying procedure without the compensation introduced by the proposed method.

\section{Acknowledgements}

The authors acknowledge that this work was financially supported by the Project of Guangdong Province support plans for top-notch youth talents, China (No.2016TQ03N704), the Project of Guangdong Province Universities and Colleges Pearl River Scholar Funded Scheme, China (No. 2016), Science and Technology Innovation fund for Graduate Students of ZhongKai University of agricultural and engineering (No. KJCX2019007), the Planned Science and Technology Project of Guangdong Province, China (Nos. 2016B020202008, 2017A040405015, and 2017B010117012), the Special Funds for the Cultivation of Guangdong College Students' Scientific and Technological Innovation. ("Climbing Program" Special Funds. No. PDJH2019B0244), the Planned Science and Technology Project of Guangzhou, China (Nos. 201704020076 and 201904010206), the Innovative Project for University of Guangdong Province (No. 2017KTSCX099), and the Key Laboratory of Spectroscopy Sensing, Ministry of Agriculture and Rural Affairs, China (No. 2018ZJUGP001).

\section{[References]}

[1] Miranda P S, Monteiro N, Pradeep V, Dsouza R, Fernandes G H. Farmer friendly drone. International Journal of Internet of Things, 2017; 6(2): 56-61.

[2] Zhou Z Y, Zang Y, Luo X W, Lan Y B, Xue X Y. Technology innovation development strategy on agricultural aviation industry for plant protection in China. Transactions of the CSAE, 2013; 29(24): 1-10. (in Chinese)

[3] He X K, Bonds J, Herbst A, Langenakens J. Recent development of unmanned aerial vehicle for plant protection in East Asia. Int J Agric \& Biol Eng, 2017; 10(3): 18-30.

[4] Wang X N, He X K, Wang C L, Wang Z C, Li L L, Wang S L, et al. Spray drift characteristics of fuel powered single-rotor UAV for plant protection. Transactions of the CSAE, 2017; 33(1): 117-123. (in Chinese)

[5] Stainier C, Destain M F, Schiffers B, Lebeau F, Stainier C. Droplet size spectra and drift effect of two phenmedipham formulations and four adjuvants mixtures. Crop Protection, 2006; 25(12): 1238-1243.

[6] Dhouib I, Jallouli M, Annabi A, Marzouki S, Gharbi N, Elfazaa S, et al. From immunotoxicity to carcinogenicity: the effects of carbamate pesticides on the immune system. Environmental Science and Pollution Research, 2016; 23(10): 9448-9458.

[7] Zhou Y, Niu M, Li J, Xu X, Sun Z, Xue K. Influence of lateral wind and electrostatic voltage on spray drift of electrostatic sprayer. Transactions 
of the CSAE, 2015; 31(24): 39-45. (in Chinese)

[8] Nádasi P, Szabó I. On-board applicability of mems-based autonomous navigation system on agricultural aircrafts. Hungarian Journal of Industry and Chemistry, 2011; 39(2): 229-232.

[9] Garcerá C, Moltó E, Chueca P. Spray pesticide applications in Mediterranean citrus orchards: Canopy deposition and off-target losses. Sci. Total Environ, 2017; 599-600: 1344-1362.

[10] Wang C L, He X K, Wang X N, Bonds J, Herbst A, Wang Z G, et al. Testing method of spatial pesticide spraying deposition quality balance for unmanned aerial vehicle. Transactions of the CSAE, 2016; 32(11): 54-61. (in Chinese)

[11] Heidary M A, Douzals J P, Sinfort C, Vallet A. Influence of spray characteristics on potential spray drift of field crop sprayers: A literature review. Crop Protection, 2014; 63: 120-130.

[12] Faiçal B S, Costa F G, Pessin G, Ueyama J, Freitas H, Colombo A, et al. The use of unmanned aerial vehicles and wireless sensor networks for spraying pesticides. Journal of Systems Architecture, 2014; 60(4): 393-404

[13] Torrent X, Garcerá C, Moltó E, Chueca P, Abad R, Grafulla C, et al. Comparison between standard and drift reducing nozzles for pesticide application in citrus: Part I. Effects on wind tunnel and field spray drift. Crop Protection, 2017; 96: 130-143.

[14] Foqué D, Baekman P, Pieters J G, Nuyttens D, Nuyttens D. A vertical spray boom application technique for conical bay laurel (Laurus nobilis) plants. Crop Protection, 2012; 41: 113-121.

[15] Zhao H, Xie C, Liu F, He X K, Song J L. Effects of sprayers and nozzles on spray drift and terminal residues of imidacloprid on wheat. Crop Protection, 2014; 60(60): 78-82.

[16] Mercer G M. Modelling to determine the optimal porosity of shelterbelts for the capture of agricultural spray drift. Environmental Modelling and Software, 2009; 24(11): 1349-1352.

[17] Cock N D, Massinon M, Salah S O T, Lebeau F. Investigation on optimal spray properties for ground based agricultural applications using deposition and retention models. Biosystems Engineering, 2017; 162: 99-111.

[18] Hilz E, Vermeer A W P. Spray drift review: The extent to which a formulation can contribute to spray drift reduction. Crop Protection, 2013; 44(1): 75-83

[19] Miranda-Fuentes A, Marucco P, González-Sánchez E J, Cil E, Grella M, Balsari P. Developing strategies to reduce spray drift in pneumatic spraying in vineyards: Assessment of the parameters affecting droplet size in pneumatic spraying. Sci. Total Environ, In Press, Corrected Proof, 2017; 616: 1-11.

[20] Faial B S, Freitas H, Gomes P H, Mano L Y, Pessin G, Carvalho A C P L F, et al. An adaptive approach for UAV-based pesticide spraying in dynamic environments. Computers and Electronics in Agriculture, 2017; 138(C): 210-223.

[21] Wang X N. Study on spray drift and anti-drift method. Beijing: China Agriculture University, 2017. (in Chinese)

[22] Heidary M A, Douzals J P, Sinfort C, Vallet A. Influence of nozzle type, nozzle arrangement and side wind speed on spray drift as measured in a wind tunnel. Ageng, 2014; 6: 1-7.

[23] Alves G S, Kruger G R, Cunha J P A R., Santana D G, Pinto L A T, Guimaraes F, et al. Dicamba spray drift as influenced by wind speed and nozzle type. Weed Technology, 2017; 31: 724-731.

[24] Ellis M C B, Alanis R, Lane A G, Tuck C R, Nuyttens D, Zande J C. Wind tunnel measurements and model predictions for estimating spray drift reduction under field conditions. Biosystems Engineering, 2017; 265: $25-34$.

[25] Wu X F. Study and design of high-resolution sigma-delta ADC. Xi'an: Xidian University, 2009. (in Chinese)

[26] Aldarouich A, Yuan H W. Design of scale model mechanism in low speed wind tunnel. Computer Aided Drafting Design and Manufacturing, 2008; 2 : 57-64.

[27] Smith D B, Askew S D, Morris W H, Boyette M. Droplet size and leaf morphology effects on pesticide spray deposition, Transactions of the ASAE, 2000; 43: 255-259.

[28] Wood K T, Cheung R M, Richardson T, Cooper J. A new gust generator for a low speed wind tunnel: Design and commissioning. AIAA Aerospace Sciences Meeting, Grapevine, Texas, 2017.

[29] Garcerá C, Román C, Moltó E, Abad R, Insa J A, Torrent X, et al. Comparison between standard and drift reducing nozzles for pesticide application in citrus: Part II. Effects on canopy spray distribution, control efficacy of Aonidiella aurantii, (Maskell), beneficial parasitoids and pesticide residues on fruit. Crop Protection, 2017; 94(2): 83-96.

[30] McGinty J A, Baumann P A, Hoffmann W C, Fritz B K. Evaluation of the spray droplet size spectra of drift-reducing agricultural spray nozzle designs. American Journal of Experimental Agriculture, 2016; 11(3): $1-5$ 